\title{
Manejo de vía aérea en gastrostomía endoscópica percutánea en paciente con parálisis espástica post ACV
}

Ianna JA. ${ }^{1}$

1 Hospital regional doctor Ramón Carrillo, Santiago del Estero, Argentina.

Introducción: El manejo de la vía aérea es una de las herramientas fundamentales en nuestra especialidad, es por ello, que se propone como objetivo la actualización permanente respecto al manejo de la misma, protocolos, algoritmos, simulaciones y sobre la toma de decisiones.

Descripción del caso: Un paciente masculino de 60 años, $55 \mathrm{~kg}$. ASA III, programado para gastrostomía endoscópica percutánea. Como antecedentes posee Hipertensión Arterial crónica sin tratamiento, Accidente Cerebro Vascular isquémico hace 8 años, con secuela de parálisis Faciobraquiocrural por lo que se encuentra postrado; y por último, un episodio de Neumonía Intrahospitalaria el mes previo. Al examen físico: AR: disminución bilateral de aire leve. ACV: Soplo sistólico mitral. SNC: Glasgow 10/15 afasia de expresión y comprensión. Vigíl Pupilas isocóricasreactivas. Semiología de vía aérea: Apertura bucal regular. Mallampatti IV. Información adicional: Accesos venosos malos. Laboratorio normal. Radiografía tórax infiltrado bilateral. Se administra $100 \mu \mathrm{g}$ de fentanilo y $120 \mathrm{mg}$ de propofol. Oxigenación con cánula nasal con $\mathrm{O} 2 \mathrm{al} 40 \%$.

Comentarios: El paciente a los dos minutos de empezar el procedimiento, comienza a desaturar hasta llegar a $75 \%$, por lo que se decide extraer el endoscopio y reemplazar la cánula nasal por un circuito de Mapleson tipo B; al cabo de 30 segundos aumenta saturación al 100\%. Luego se reanuda el procedimiento y concluye con normalidad.

Discusión: Hay mucha controversia respecto al manejo de la vía aérea en estos pacientes (ASA III) ante estos procedimientos. Considero que faltan más protocolos y algoritmos más específicos para estas situaciones para una adecuada toma de decisiones.

https://doi.org/10.25237/congresoclasa2019.58 